Topical Review

\title{
Owner's Perception for Detecting Feline Body Condition Based on Questionnaire and Scores
}

\author{
Letícia Peron, Grd DVM ${ }^{a}$, Sheila C. Rahal, PhD, MSc, DVM ${ }^{a, *}$, \\ Maíra S. Castilho, Pst-Grd, DVM ${ }^{a}$, Alessandra Melchert, PhD, MSc, DVM ${ }^{\mathrm{b}}$, \\ Flávia G. Vassalo, MSc, DVM ${ }^{a}$, Luciane R. Mesquita, PhD, MSc, DVMa , \\ Washington T. Kano, MSc, DVM ${ }^{a}$
}

Keywords:

obesity

cat

activities

body score

${ }^{a}$ Department of Veterinary Surgery and Anesthesiology, School of Veterinary Medicine and Animal Science, Univ Estadual Paulista (UNESP), Botucatu, SP, Brazil

${ }^{b}$ Department of Veterinary Clinic, School of Veterinary Medicine and Animal Science, Univ Estadual Paulista (UNESP), Botucatu, SP, Brazil *Address reprint requests to Sheila C. Rahal, $\mathrm{PhD}, \mathrm{MSc}$, DVM, Department of Veterinary Surgery and Anesthesiology, School of Veterinary Medicine and Animal Science, Univ Estadual Paulista (UNESP), Rubião Júnior s/n, 18618970 Botucatu, SP, Brazil. E-mail: sheilacr@fmvz.unesp.br (S.C. Rahal)
To evaluate the owner's ability to identify body condition in cats, based on questionnaire and scores, as well as to obtain others' information about the cat and the owner that may be related to the body condition. Seventyseven owned cats, aged above 11 months, were evaluated. Initially, information was obtained on age, sex, breed, and whether they had been neutered. Next, owners were asked to fill a questionnaire: the first section was about the cat's diet type, feeding regime, and activity level, and the second section was on the owners' diet, physical activity, and physical condition. The owners estimated body condition of their cats before and after seeing drawings with images. The authors also estimated body condition. Only a 5-point visual scale showed significant difference between the cat's body score assigned by the owner before and after seeing drawings, and before seeing drawings compared with the cat's body score assigned by the authors. A weak positive correlation was detected between cat's body score assigned by the 2 authors and access to any type of cat climbing systems, and weak negative correlation was detected for the variable spayed or neutered. The cat's physical activity level showed weak negative correlation with cat's body score. There was a strong positive correlation between cat's body weight and cat's body score. The owners showed ability to identify body condition in cats after seeing the drawings in both visual scales, and there was a relationship between cat's body weight and body condition score.

(c) 2016 Elsevier Inc. All rights reserved.

\section{Introduction}

Excess weight has been associated with various health problems including osteoarthritis, diabetes mellitus, respiratory problems, heart disease, and cancer among others. ${ }^{1-6}$ Apparently, overweight cats are 3 or 4 times more likely to develop diabetes than those of normal weight. ${ }^{1,5}$ There is also a relation between overweight and skin disorders, including alopecia, feline acne, and scale development, probably on account of diminished selfgrooming ability, and pressure sores due to reduced activity. ${ }^{5}$

The management of obesity depends on the development of a negative energy balance including proper diet, behavioral changes, and increased physical activity. ${ }^{6} \mathrm{~A}$ treatment plan that would satisfy the corresponding needs for both patient and owner must be developed. ${ }^{1,7}$ However, for this to occur, the problem must be recognized. ${ }^{1,6,7}$ The various methods for measuring body composition that differ according to their applicability include research, evaluation by a clinical specialist, or first evaluation by a nonspecialist. ${ }^{2}$ From a clinical point of view, the evaluation can be performed by combining body weight and use of body condition scores. ${ }^{6}$ On the one hand, the body weight moderately correlates with body fat mass. ${ }^{5}$ On the other hand, the body condition scoring system can be a tool for educating cat owners about the prevention and management of obesity,

Supported in part by CNPq, Brazil (National Council for Scientific and Technological Development-PIBIC 117025/2014-3, and PQ 300710/2013-5). because the owners are often unable or unwilling to recognize overweight or obesity in their pets.

Therefore, the aim of this study was to evaluate the owner's ability to identify body condition in cats, based on questionnaire and scores, as well as to obtain others' information about the cat and the owner that may be related to the body condition.

\section{Materials and Methods}

\section{Cat Selection}

The study was approved by the Ethics Committee of our Veterinary School (No. 37/2014). A signed Informed Consent Form was requested from each cat's owner, before entering the study.

Seventy-seven owned cats, females and males, intact or spayed or neutered, and aged above 11 months were evaluated. The cats were selected independent of their body condition or age. The inclusion criterion was healthy cats or cats with clinical disorders that did not interfere in the research. The interviews were conducted mostly at the Veterinary School, with others being conducted door-to-door in the same city and in 2 other cities at respective distances of approximately 200 and $116 \mathrm{~km}$ from the Veterinary School.

\section{Questionnaire}

Initially, information was obtained on the animals in relation to age, sex, breed, and whether they had been spayed or neutered. 
Afterward, the owners were asked to fill a questionnaire (Supplementary 1 ), the first section of which gathered information about the cat, including diet type, feeding regime, and activity level. In the second section, the owners had to provide information about their own diet, physical activity, and physical condition. The owners were then asked to estimate body condition of their cats before and after seeing drawings of both 5-point and 9-point visual scales for cats, respectivelly. ${ }^{9-12}$ After owner's evaluation, the cat's body condition was evaluated always by 2 of the authors using the 5-point and 9-point visual scales, respectivelly. ${ }^{12}$ In addition, all cats were weighed using the same electronic scale.

\section{Statistical Methods}

To compare cat's body score assigned by the owner with score assigned by the 2 authors, before and after seeing drawings, was used the Spearman correlation for both 5-point and 9-point visual scales. In addition, Mann-Whitney $U$ test was used to compare cat's body score assigned by the owner, before and after seeing drawings of both visual scales, with the cat's body score being assigned by the 2 authors. Wilcoxon test was used to compare cat's body score assigned by the owner before and after seeing drawings of both visual scales.

Spearman correlation coefficient was used to evaluate cat's body score assigned by the same authors (9-point visual scale) with owner's information (level of physical activity, diet, and physical condition), as well as cat's information (age, sex, intact, or spayed or neutered; physical activity, climbing system, places where they live, access to outdoor, diet type, feeding regime, diameter of the food bowl, determination of food intake, and snack food). Pearson correlation was used to evaluate cat's body score assigned by authors (9-point visual scale) with cat's body weight. Differences were considered significant at $P<0.05$.

Statistical analyses were conducted using the statistical software GraphPad Prism version 5.0 (San Diego, CA).

\section{Results}

Among all cats, 49 were aged from 11 months to 5 years 11 months, 18 from 6 years to 11 years 11 months, 9 aged above 12 years, and 1 cat was of unknown age. The average weight of the cats was $4.35 \mathrm{~kg}$ (standard deviation $=1.09$ ). A total of $49 \%$ of the cats weighed between 3.5 and $4.5 \mathrm{~kg}$. Aside from 5 Siamese, 2 Persians, 2 Birmans, and 1 Himalayan, all cats were crossbred. Considering the sex, $62 \%$ were spayed females and $38 \%$ were males (5 intact and 24 neutered).

The activity level per day of the cats was $57 \%$ up to 1 hour, $25 \%$ up to 10 minutes, $14 \%$ none, and $4 \%$ more than 1 hour. The access to any type of cat climbing systems occurred in $88 \%$, and none for $12 \%$ of the animals. The cats that lived in a house with access to the backyard comprised $74 \%$ vs. $26 \%$ in an apartment or house without access to the backyard. Most of the cats did not have access to the outdoors (69\%), whereas $26 \%$ had access and $5 \%$ were alone.

Approximately $74 \%$ of the cats ate dry commercial food, $25 \%$ ate wet and dry commercial food, and $1 \%$ ate homemade food. Among the cats that ate commercial food, 24 of them ate a cat food for neutered cats. The feeding regime was controlled only in $39 \%$ of cases; whereas in $75 \%$, the diameter of the food bowl was up to $15 \mathrm{~cm}$. The cat's food intake was $60 \%$ as free access, $21 \%$ had 3 or more meals per day, $12 \%$ had 2 meals per day, and $8 \%$ had 1 meal per day. The determination about how much the cat should eat was based on the owner's experience in $60 \%$ of cases, veterinarian indication in $18 \%$, and according to food packaging label in $8 \%$. The snack food was not offered to $29 \%$ of the cats, $46 \%$ of the cats ate snack once in a week, and $25 \%$ of the cats ate it daily.

Of the 77 cats, $45 \%$ were rarely maintained alone without the owner, $42 \%$ most of the day, and $13 \%$ part of the time. However, $80 \%$ of the cats coexisted with other animals. The owners who considered overweight or obesity as a potential problem were $97 \%$, $1 \%$ did not know, and $1 \%$ did not consider it a risk. Approximately $61 \%$ of the owners agreed to submit the cat to a weight loss program, $12 \%$ did not agree because they would not have support of the other family members, and $27 \%$ did not agree for other reasons.

The level of physical activity of the owner was classified as none in $14 \%$, only on weekends in $9 \%$, occasional in $6 \%$, up to 3 hours per week in 35\%, up to 6 hours per week in $25 \%$, and as intense in $10 \%$. The owner's diet was considered healthy most of the time, that is, $65 \%, 24 \%$ were daily healthy, and in $10 \%$ there was no control. For $3 \%$ of the owners, their physical condition was underweight, $52 \%$ were normal, and $45 \%$ were overweight or obese.

By means of the 9-point visual scale, the authors observed that $58 \%(45 / 77 ; 29$ females and 16 males of 45$)$ had scores of $6-9,32 \%$ scored $4-5$, and $9 \%$ scored $1-3$. Cat's body score assigned by the owner before and after seeing drawings of both visual scales showed statistically significant difference only after seeing drawings of 5-point visual scale. Cat's body score assigned by the owner, before and after seeing drawings of both visual scales, compared with the cat's body score being assigned by the 2 authors showed no statistically significant difference using 9-point visual scale, but statistically significant difference $(P=$ 0.015 ) was observed using 5-point visual scale only before seeing drawings.

The correlation coefficient between cat's body score assigned by the owner and cat's body score assigned by the 2 authors showed significant positive correlation before $(r=0.499)$ and after $(r=0.736)$ seeing 5 -point visual scale drawings, and before $(r=0.554)$ and after $(r=0.721)$ seeing 9 -point visual scale drawings.

No correlation was detected between the cat's body score (9-point visual scale) and cat's information such as age, sex, places where they live, access to outdoor, diet type, feeding regime, diameter of the food bowl, determination of food intake, snack food).

A weak positive correlation was detected between cat's body score assigned by the 2 authors and access to any type of cat climbing systems $(r=0.245)$, and weak negative correlation for the variable spayed or neutered $(r=-0.238)$. The cat's physical activity level showed weak negative correlation with cat's body score $(r=-0.248)$. There was a strong positive correlation between cat's body weight and cat's body score $(r=0.652)$.

No correlation was detected between the cat's body score (9-point visual scale) and owner's information (level of physical activity, diet, and physical condition).

\section{Discussion}

Several body condition scoring systems have been developed, but the most frequently used are the 5-point visual scale (where a score of 3 corresponds to the ideal body weight) and 9-point visual scale (where a score of 5 corresponds to ideal body weight), ${ }^{2,5,8,12}$ which were used in the present study. The limitations of these systems are the subjectivity that can promote variation between observers as well as an occasional need for previous training in morphometric evaluations. ${ }^{5}$ In the present study, a strong correlation between cat's body score assigned by the owner and cat's body score assigned by the 2 authors in both visual scales occurred after seeing the drawings. In addition, in a 
study of an urban population of cats it was observed that body condition evaluated by the owners was better when using an analog to the 5-point visual scale than a verbal description. ${ }^{13}$

In the present study, only a 5-point visual scale showed significant difference between the cat's body score assigned by the owner before and after seeing drawings, and before seeing drawings compared with the cat's body score assigned by the authors, suggesting that 9-point visual scale was better to evaluation. On the contrary, agreement between experienced operators and owners (inexperienced) was reported in a study that used a 7-point algorithm system to determine body condition scoring. ${ }^{2}$

Among a population of 8159 adult cats, 35\% were considered overweight or obese, ${ }^{4}$ whereas another study of 385 cats found $19 \%$ overweight and $7.8 \%$ obese. ${ }^{13}$ The present study presented a higher prevalence as it was based on the evaluators' assessment by the 9-point visual scale, $58 \%(n=45)$ of the cats were overweight or obese. Furthermore, in a study assessing a population of 136 cats, $48 \%$ were overweight and $8 \%$ were obese. ${ }^{14}$ In general, it is considered that neutered males face greater risk for overweight or obesity. ${ }^{13,15,16}$ In the present study, a weak negative correlation was observed between the feline body score assigned by the 2 authors and the intact or spayed or neutered condition. However, among the overweight or obese cats, 13 were males and 32 were females, and all were spayed or neutered.

Inactivity and a low activity level are considered risk factors for obesity. ${ }^{15,17}$ In the present study, the cat's body score assigned by the 2 authors showed a weak negative correlation with the daily physical activity, and a weak positive correlation with access to any type of cat climbing systems. Thus, a higher cat's level of daily physical activity was associated with lower feline body score. Apparently, the energy balance may be improved by spending energy on hunting. ${ }^{18}$ In the present study, the highest level of activity was $57 \%$ up to 1 hour, although $74 \%$ and $88 \%$ of the cats, respectively, had access to the backyard and any type of cat climbing systems.

A study reported an increase of obesity in cats when no dog lived in the household, ${ }^{17}$ whereas another found that cats living in houses with 1 or 2 other cats and mainly kept inside are more likely to be overweight. ${ }^{16}$ In the present study, $80 \%$ of the cats lived with other animals (cat or dog or with both), but no correlation was observed between the cat's body score assigned by the 2 authors and time during which the cat stays alone during the day.

The feeding management of cats may have an effect on the risk of obesity, ${ }^{17}$ especially if the food is maintained ad libitum. ${ }^{14}$ Although no correlation was found between the feline body score assigned by the 2 authors and diet type; the amount, frequency, and type of food intake; or food bowl diameter, it should be emphasized that $61 \%$ of the cats did not have a controlled feeding, and $60 \%$ of the cats had free access to daily food.

The owners' variables (level of physical activity, diet, and physical condition) did not present any correlation with the feline body score. An interesting fact is, although $65 \%$ of the owners considered their diet to be healthy, $45 \%$ of them were overweight or obese and only $10 \%$ reported intense physical activity. Therefore, this may be one of the factors that influence the understanding of the owner about the influence of cat food on body score.

Some of the limitations of this study include the relatively small sample of males and population composed most of crossbred cats.

In conclusion, the owners showed ability to identify body condition in cats after seeing the drawings in both visual scales, and there was relationship between cat's body weight and body condition score.

\section{Appendix A. Supplementary material}

Supplementary data are available in the online version of this article at http://dx.doi.org/10.1053/j.tcam.2016.08.008

\section{References}

1. Laflamme DP. Nutrition for aging cats and dogs and the importance of body condition. Vet Clin North Am Small Anim Pract 35:713-742, 2005

2. German AJ. The growing problem of obesity in dogs and cats. J Nutr 136: 1940S-1946S, 2006

3. Zoran DL. Obesity in dogs and cats: a metabolic and endocrine disorder. Vet Clin North Am Small Anim Pract 40:221-239, 2010

4. Lund EM, Armstrong PJ, Kirk CA, Klausner JS. Prevalence and risk factors for obesity in adult cats from private US Veterinary Practices. Intern J Appl Res Vet Med 3:88-96, 2005

5. Case LP, Daristotle L, Hayek MG, Raash ME. Development and treatment of obesity. In: Case LP, Daristotle L, Hayek MG, Raasch MF, editors. Canine and Feline Nutrition. 3rd ed. St. Louis: Mosby Elsevier; 313-342, 2011

6. Laflamme DP. Nutritional care for aging cats and dogs. Vet Clin North Am Small Anim Pract 42:769-791, 2012

7. Laflamme DP. Understanding and managing obesity in dogs and cats. Vet Clin North Am Small Anim Pract 36:1283-1295, 2006

8. Cave NJ, Allan FJ, Schokkenbroek SL, Metekohy CA, Pfeiffer DU. A crosssectional study to compare changes in the prevalence and risk factors for feline obesity between 1993 and 2007 in New Zealand. Prev Vet Med 107: $121-133,2012$

9. Baldwin K, Bartges J, Buffington T, et al. AAHA nutritional assessment guidelines for dogs and cats. J Am Anim Hosp Assoc 46:285-296, 2010

10. Bjornvad CR, Nielsen DH, Armstrong PJ, et al. Evaluation of a nine-point body condition scoring system in physically inactive pet cats. AJVR 72:433-437, 2011

11. Laflamme DP. Development and validation of a body condition score system for cats: a clinical tool. Feline Pract 25:13-18, 1997

12. Freeman L, Becvarova I, Cave N, et al. 2011 Nutritional assessment guidelines. J South African Vet Assoc 84:254-263, 2011

13. Colliard L, Paragon BM, Lemuet B, Bénet JJ, Blanchard G. Prevalence and risk factors of obesity in an urban population of healthy cats. J Feline Med Surg 11: 135-140, 2009

14. Russell K, Sabin R, Holt S, Bradley R, Harper EJ. Influence of feeding regimen on body condition in the cat. J Small Anim Pract 41:12-17, 2000

15. Scarlett JM, Donoghue S, Saidla J, Wills J. Overweight cats: prevalence and risk factors. Int J Obes Relat Metab Disord 18:S22-S28, 1994

16. Robertson ID. The influence of diet and other factors on owner-perceived obesity in privately owned cats from metropolitan Perth, Western Australia. Prev Vet Med 40:75-85, 1999

17. Allan FJ, Pfeiffer DU, Jones BR, Esslemont DHB, Wiseman MS. A cross-sectional study of risk factors for obesity in cats in New Zealand. Prev Vet Med 46:183-196, 2000

18. Donoghue S, Scarlett JM. Diet and feline obesity. J Nutr 128:2776S-2778S, 1998 